Review Article

\title{
Agricultural and Forest Residues towards Renewable Chemicals and Materials Using Microwave Liquefaction
}

\author{
Huijuan Shao, ${ }^{1}$ Hongli Zhao, ${ }^{2}$ Jiulong Xie $\mathbb{D}^{1},{ }^{1}$ Jinqiu Qi, ${ }^{1}$ and Todd F. Shupe ${ }^{3}$ \\ ${ }^{1}$ College of Forestry, Sichuan Agricultural University, Chengdu 611130, China \\ ${ }^{2}$ College of Materials Science and Art Design, Inner Mongolia Agricultural University, Mongolia 010018, China \\ ${ }^{3}$ Wood Science Consulting, LLC, Baton Rouge, LA 70816, USA
}

Correspondence should be addressed to Jiulong Xie; jxie6@sicau.edu.cn

Received 26 June 2019; Accepted 24 August 2019; Published 9 October 2019

Academic Editor: Victor H. Perez

Copyright (c) 2019 Huijuan Shao et al. This is an open access article distributed under the Creative Commons Attribution License, which permits unrestricted use, distribution, and reproduction in any medium, provided the original work is properly cited.

\begin{abstract}
Microwave-assisted liquefaction is regarded as a promising thermochemical approach to produce renewable and sustainable chemicals and materials from lignocellulosic biomass. Agricultural and forest residues as sources of lignocellulosic biomass have great potential in this regard. With process optimizations, several biomass types have been subjected to liquefaction in different solvents with various catalysts. The products from recent microwave liquefaction with and without further fractionation have been thoroughly analyzed and used for the synthesis of biomaterials. Renewable chemicals, polyurethane foams with partial use of renewable raw materials, and phenolic resins have been the main products from microwave-liquefied products. Further research on microwave liquefaction mechanisms and scalable production should be enhanced to fully evaluate the economic and environmental benefits. This work presents an overview on achievements using liquefaction in combination with microwave energy to convert lignocellulosic biomass into value-added products and chemicals.
\end{abstract}

\section{Introduction}

Fuels, chemicals, and polymers derived from renewable and sustainable lignocellulosic biomass have attracted great interest because of the environmental issues caused by the extensive use of fossil fuels $[1,2]$. Agricultural and forest processing residues are generally regarded as a green, renewable, and sustainable resource [3]. According to Zhang, in China, the bioenergy from agricultural and forest residues is made up of agriculture $(74 \%)$ and forest $(22 \%)$. The bioenergy potential of crop straw is equal to that of 201 million tons of standard coal $(48.98 \%)$, followed by forestry residue (22\%) and agricultural processing residues $(12 \%)$, revealing that agricultural and forest residues have great potential for energy, chemical, and material production [4]. Generally, lignocellulosic biomass is mainly composed of cellulose, hemicellulose, and lignin, and their proportion differs in the types of forest and agricultural residues. For wood, the proportion of cellulose, hemicellulose, and lignin ranges from 25\% (olive tree pruning) to $43.8 \%$ (spruce), $6.3 \%$ (spruce) to $28.5 \%$ (pinewood), and $16.2 \%$ (olive tree pruning) to $29.1 \%$ (red maple), respectively. As for agricultural residues, the proportion of the three components is $14.3 \%$ (corn fiber) to $43.1 \%$ (sugarcane bagasse), $16.8 \%$ (corn fiber) to $37.2 \%$ (barley hull), and $4.7 \%$ (corn pericarp) to $24.8 \%$ (bagasse), respectively [5]. Cellulose consists of a linear homopolysaccharide composed of $\beta$-D-glucopyranose units linked together by $\beta$ 1-4 linkages (glucosidic bonds), and hemicelluloses are polysaccharides consisting of $\beta$ - $(1 \rightarrow 4)$-linked backbones. Lignin is composed of three different phenyl propane units, namely, syringyl alcohol, guaiacyl alcohol, and p-coumaryl alcohol [6]. The native chemical structures of lignocellulosic biomass make lignocellulosic biomass the source of sustainable products.

With the rapid development of thermochemical conversions of lignocellulosic biomass, the utilization of lignocellulosic biomass includes the fabrication of composites, either with or without nonbiobased feedstocks, to the generation of fine chemicals and renewable energy (Figure 1). Thermochemical conversion methods including combustion, gasification, pyrolysis, and liquefaction are common pathways in 


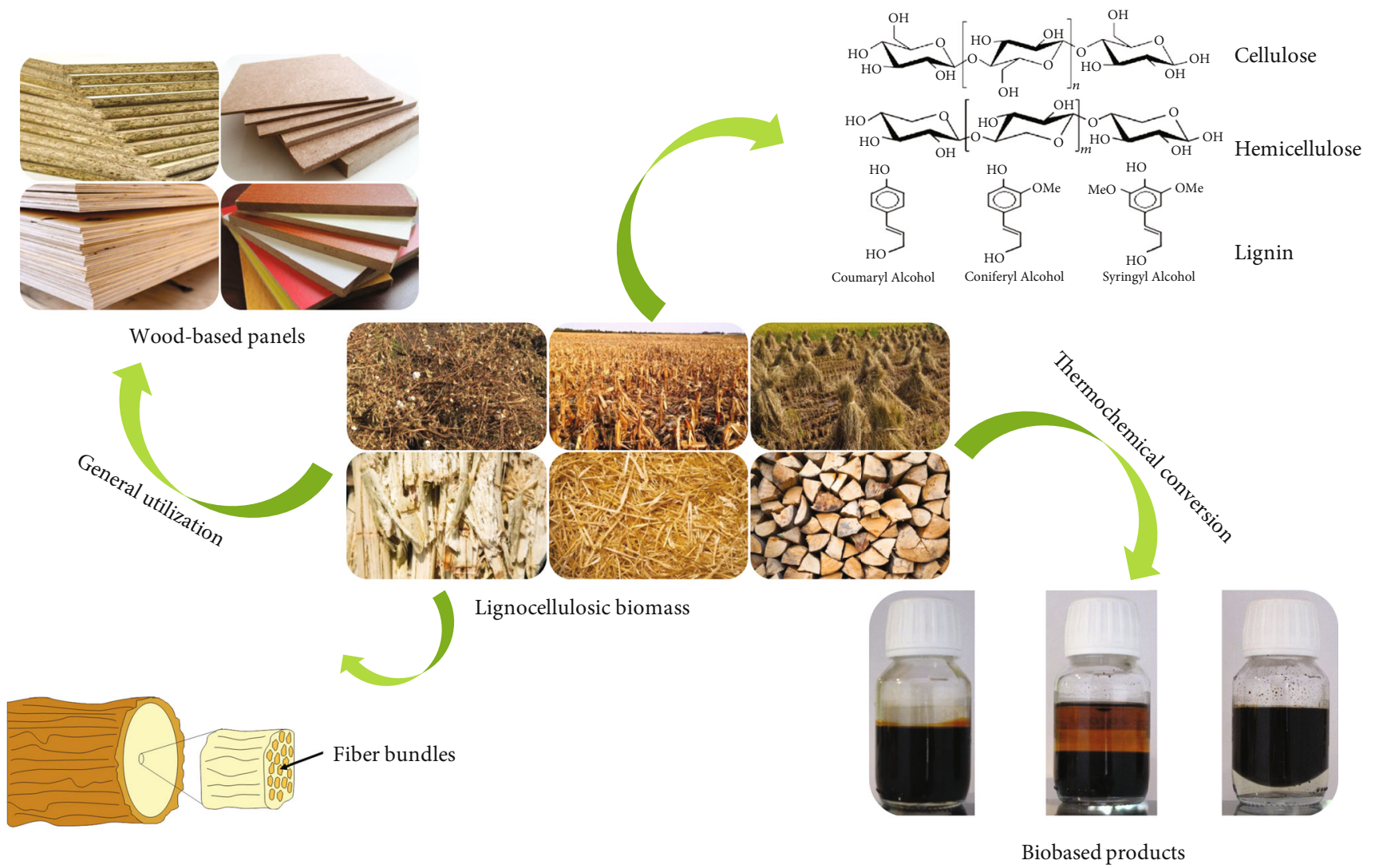

Figure 1: Products of lignocellulosic biomass.

converting lignocellulosic biomass to renewable energy and chemicals [7]. For comparison, liquefaction is generally carried out in organic solvents at a relatively low temperature to convert lignocellulosic biomass into small molecular substances; meanwhile, liquefaction products are directly used as ingredients or refinement for further usage [2].

This paper gives an overall report on lignocellulosic biomass sources and liquefaction reagents used in microwave liquefaction as well as process optimization. In addition, the analysis and applications of microwave-liquefied products are also summarized and discussed. This review mainly summarizes the recent research achievements on microwave-assisted liquefaction of lignocellulosic biomass and is anticipated to initiate further research to facilitate the production of renewable chemicals and materials from microwave liquefaction.

\section{Microwave Liquefaction versus Conventional Liquefaction}

The conventional liquefaction process of lignocellulosic biomass was carried out using conduction/convection heating by oil bath or heating mantle, which usually requires a long reaction time and yields a low liquefaction rate, resulting in low efficiency. In order to have a more complete reaction in conventional liquefaction, large amounts of solvents such as phenol have typically been used but are inconsistent with an environmentally friendly and sustainable concept [8-12].
Microwave irradiation is categorized as electromagnetic irradiation in the range of wavelengths from $0.01 \mathrm{~m}$ to $1 \mathrm{~m}$ with corresponding frequency of 300-0.3 gigahertz $(\mathrm{GHz})$ [13]. Microwave heating is the direct coupling of microwave energy with molecules. Therefore, microwave heating occurs over the entire volume of material. Due to the advantages of microwave heating, microwave irradiation method have been applied to chemical synthesis [14], extraction [15, 16], gasification [17], pyrolysis [18], and liquefaction [19, 20]. Compared with conventional liquefaction, microwave-assisted liquefaction is more efficient. Previous research had shown that the application of microwave energy on liquefaction could enhance the liquefaction extent [19-22]. Previous research also indicated that microwave heating influenced the properties of the liquefied products; chemicals from microwave liquefaction processed much smaller average molecular weight compared with those from conventional liquefaction $[21,23]$.

\section{Lignocellulosic Biomass Sources for Microwave Liquefaction}

3.1. Biomass Type. Since Krzan et al. first applied microwave energy to liquefaction $[19,20]$, a variety of biomass types including sweetgum sawdust [8]; agricultural residues including bagasse, corn stover, rice straw, wheat straw, cotton stalk, and corncobs [24-26]; organosolv lignin of olive tree prunings [27]; Sargassum polycystum C. Agardh [28]; microalgae [29]; Ulva prolifera [30]; wheat straw alkali lignin 
[31]; sugar beet pulp [32]; peony oil palm empty fruit bunch fiber [16]; oil palm empty fruit bunch cellulose [33]; poplar; Chinese fir; bamboo; hemp xyloid stem [22]; mixed softwood pellets [34]; banana pseudostem [35]; coconut fiber [36]; and grapefruit [37] have been studied as raw materials for microwave-assisted liquefaction for the production of renewable chemical platforms and/or biobased materials.

The chemical composition (cellulose, hemicellulose, lignin, and ash) and microstructure of the lignocellulose feedstocks greatly differed with each other, which may influence their liquefaction behaviors under microwave heating. Studies have shown that the conversion yield of corn stover, rice straw, and bagasse is variable [12, 24, 38, 39]. Xiao et al. [25] made a comparison of the liquefaction behaviors of different agricultural crop residues under the same microwave-assisted liquefaction conditions, and the results revealed that the liquefaction rate of rice straw was much lower than that of wheat straw, corn stover, and corncobs. $\mathrm{Li}$ et al. studied five types of microwave-liquefied biomass, and the results showed that poplar and Chinese fir were the most easily liquefied, followed by bamboo and hemp xyloid stem. While comparing with the other four feedstock materials, the rice straw exhibited the lowest liquefaction degree [22].

Research results on microwave liquefaction of bamboo showed that the liquefied bamboo residue rate could be less than 5\% [40,41]. Despite the high liquefaction rate of bamboo in different solvents under microwave heating, further study revealed that the higher percentages of thin cell wall tissues as well as lower cellulose and lignin contents resulted in a lower residue content. It indicated that the anatomical characteristic and chemical components could affect the microwave-assisted liquefaction process of bamboo $[42,43]$. The difference in the conversion yield between the liquefaction of poplar, fir, and woody underbrush may also provide evidence that structure and chemical compositions can influence the liquefaction behaviors since significant differences exist between softwood, hardwood, and agricultural residues [40, 44-47].

Similar to the varying liquefaction results for different ligneous plants, the species of microalgae was also found to be an important factor. Other raw materials that have been studied and found to influence liquefaction conversion and product properties include type of waste paper and source of lignin $[27,28,30,48,49]$.

3.2. Biomass Particle Size. The use of small particle size greatly improved the liquefaction efficiency and reduced the amount of the solvent required. Zheng et al. found that the liquefied residue content of sugar beet pulp with a particle size of 75-177 $\mu \mathrm{m}$ reduced much faster than that with a size of 177-841 $\mu \mathrm{m}$ [32]. Li found that when the particle size of poplar wood decreased from $0.38-0.83 \mathrm{~mm}$ to 0.18 $0.25 \mathrm{~mm}$, the liquefaction rate increased from $58.5 \%$ to $87.0 \%$ [45]. The results on microwave liquefaction of bamboo revealed that smaller size of feedstocks could shorten the time of liquefaction when the temperature was $120^{\circ} \mathrm{C}$, which may be because the smaller the particles, the easier the full material can be accessed by the solvent and lignin recondensation that occurs when the temperature is $140^{\circ} \mathrm{C}[50]$.

3.3. Moisture Content. Moisture of the raw materials is another factor that can influence liquefaction behavior. The optimal moisture content of poplar wood for microwave liquefaction in phenol was $30-40 \%$ [45]. The relation between moisture content and liquefaction yield of Ulva prolifera showed that the liquefaction yield increased with increasing moisture content and then tended to decrease with a further increase in moisture and showed a maximum at $8 \%$. This may be because the excessive moisture content caused a decrease in reaction temperature and solvent concentration, and the proper amount of moisture was beneficial to microwave absorption and hydrolysis. At the same time, water molecules are polar molecules; proper moisture content could enhance the ability of absorbing microwave energy and increase the heating rate of a wood liquefaction system [51].

\section{Liquefaction Reagents for Microwave Liquefaction}

Liquefaction reagents including solvents and catalysts are dominating factors influencing the liquefaction process [52]. Proper liquefaction reagents can make the feedstock particles more evenly dispersed in the solid-liquid system and promote the liquefaction reaction. Meanwhile, the liquefaction efficiency and product quality and applications are also largely dependent on the reagents employed.

4.1. Solvents. Compared with higher analogues, i.e., diethylene glycol, dipropylene glycol, and polyethylene glycol, simple glycols, i.e., ethylene glycol (EG) and propylene glycol (PG), showed higher liquefaction efficiency for the liquefaction of dry poplar sawdust using microwave energy. The liquefaction rates of simple glycols were $85 \%$ and $99 \%$ (EG and PG, respectively), while those of higher analogues were only 63-69\% [53]. The liquefaction efficiency of wheat straw alkali lignin in alcohols was in the decreasing order of methanol, glycol, propanol, glycerol, alcohol, and butanol, which indicated that methanol was a preferable solvent. This finding was attributed to the larger dipole moment of methanol, resulting in a better absorbance of microwave energy [31]. According to the yield of liquid products, more yield indicates better liquefaction efficiency. The use of methanol and ethanol for the liquefaction of organosolv lignin showed the best liquefaction efficiency compared to that of butanol, ethanediol, and isopropanol. Meanwhile, the molecular weight of the generated chemicals was much different. The weight average molecular weight $(\mathrm{Mw})$, number average molecular weight $(\mathrm{Mn})$, and $\mathrm{Mw} / \mathrm{Mn}$ of isopropanol were 1919, 388, and 4.95 , respectively. The Mw of butanol and ethanediol possessed similar values, 1522 and 1517, but the $\mathrm{Mw} / \mathrm{Mn}$ of ethanediol was narrower than that for butanol. The $\mathrm{Mw}$ of methanol and ethanol exhibited lower values (1164 and 1162, respectively) compared with butanol, ethanediol, 
and isopropanol. The reason may be that both methanol and ethanol are lower molecular weight alcohols, showing higher nucleophilic activity, and could promote the C-O-C cleavage of lignin in solvolytic reaction [54]. In terms of methanol, ethanol, water, polyethylene glycerol, and glycerol, with increasing the reaction temperature from $120^{\circ} \mathrm{C}$, the liquefaction yield of bamboo in polyethylene glycerol and glycerol decreased, which revealed that polyethylene glycerol and glycerol were two desirable and energy-saving liquefaction solvents under lower reaction temperature using microwave energy [55].

As the concentration of methanol in glycerol increased, the content of 5-hydroxymethylfurfural and levulinic acid decreased, and the total content of sugar derivatives showed the same trend by increasing the methanol content. An apparent conclusion was that methanol could enhance the liquefaction efficiency of the feedstocks; on the other hand, it could also prevent further decomposition of the sugar derivatives [56].

In addition to the solvent type, the ratio of solvent to solid also has an effect on liquefaction yield. The overall solvent to solid ratio in a microwave liquefaction system was lower than that in conventional liquefaction. The optimal phenol to polar wood ratio for maximum liquefaction yield and economic efficiency was 5/2 [45]. As the solvent to coconut fiber increased from $3.3: 1$ to $5: 1$, the liquefaction rate increased from $56 \%$ to $89 \%$ and remained constant with further increase in the solvent proportion [36]. The liquefaction yield of varied solvents from different raw materials are shown in Table 1. As shown in Table 1, liquefaction using glycol and methanol as cosolvent exhibited excellent liquefaction rate compared to other solvents. Besides the types of solvents being able to influence the liquefaction rate, the concentration of solvents and the ratio of dual components solvents also have an effect on the liquefaction rate.

4.2. Catalyst. A catalyst has been used in almost every liquefaction process using either conventional or microwave heating. In the liquefaction of most lignocellulosic biomass using microwave energy, sulfuric acid has been identified as a prevailing catalyst [57-60]. A variety of acids (sulfuric acid, hydrochloric acid, phosphoric acid, and formic acid) have been used in the microwave liquefaction of the components of lignocellulosic biomass. The results confirmed that sulfuric acid was also a good choice in the liquefaction of lignin [61]. Sulfuric acid was found to be the most influential factor on the conversion of lignin compared to time and lignin concentration [60]. Furthermore, sulfuric acid was more efficient for the production of monophenolic products from liquefaction of lignin than the zeolite and FeS binary catalyst [62]. Sulfuric acid, sodium hydroxide, levulinic acid, and p-toluene sulfonic acid monohydrate (PTSA) (98\%) were used in the microwave-assisted conversion of cellulose, and their efficiency was comparatively elucidated. The results indicated that sulfuric acid was a strong mineral acid catalyst and was proposed as the preferable catalyst for microwave liquefaction of cellulosic materials [63].
Kong et al. [64] studied the influence of $\mathrm{Fe}_{2} \mathrm{O}_{3}$-modified $\mathrm{HY}$ (Si/Al ratio 5.0) on the bio-oil liquefaction yield of Ulva prolifera. It was found that the doped $\mathrm{Fe}_{2} \mathrm{O}_{3}$ enhanced the total acid sites of the catalyst, which distinctly increased the bio-oil yield from 40.6 to $52.6 \%$, demonstrating that the doped amounts of $\mathrm{Fe}_{2} \mathrm{O}_{3}$ to the $\mathrm{HY}$ ( $\mathrm{Si} / \mathrm{Al}$ ratio 5.0) obviously improved the catalytic performance for the liquefaction of Ulva prolifera.

The changes in the catalyst concentration or amount in the feedstock of a microwave liquefaction system also affect liquefaction behaviors. Previous research results revealed that the liquefaction yield of biomass first increased by increasing the catalyst concentration, while further increasing the concentration the liquefaction yield decreased $[36,46]$. The proper concentration of sulfuric acid for most lignocellulosic biomass using microwave energy was 3-5\%, which was relatively lower than that used for conventional liquefaction. For example, the optimized sulfuric acid concentration for the liquefaction of Ulva prolifera and Kraft lignin was $5 \%$ and $3 \%$, respectively $[30,65]$.

\section{Microwave Liquefaction Process Optimization}

From the above, in the process of microwave liquefaction, we can conclude that raw materials, liquefaction reagents (solvents, catalysts) have significant effects on the conversion yield and the properties of the end products. On the other hand, the microwave power, liquefaction temperature, and time also affect the conversion yield and quality of the products.

5.1. Temperature and Time. Temperature and time are the main factors influencing liquefaction behaviors and properties of the liquefied products in the microwave heating system. The effect on the liquefaction yield of rice straw was in the decreasing order of reaction temperature, catalyst amount, solvent to solid ration, reaction time, phenol to glycerol ratio, and microwave power [38]. With microwave liquefaction of rice straw, temperature was identified as the most influential factor. A study on the microwave liquefaction of poplar wood sawdust also indicated that the most influential factor was temperature [44]. Research results on the microwave liquefaction of other lignocellulosic biomass also revealed that the most important factor influencing the liquefaction was temperature $[24,41,58$, $66,67]$. The depolymerization of ethanol organosolv lignin from bamboo with low-power microwave showed that temperature was more influential than reaction time [68]. The significant microwave liquefaction factor is temperature, and the reason may be that temperature enhances and attacks solvents and catalysts onto glycosidic linkages resulting in the decomposition of cellulose into small molecules [69].

The optimum liquefaction temperature and time for oil empty fruit bunch fiber and oil palm empty fruit bunch fiber cellulose was $160^{\circ} \mathrm{C}$ with $15 \mathrm{~min}$ and $175^{\circ} \mathrm{C}$ with $40 \mathrm{~min}$ [33]. The research results on the liquefaction of coconut fiber indicated that the optimal reaction temperature was $160^{\circ} \mathrm{C}[36]$. 
TABLE 1: Liquefaction yield of varied solvents from different raw materials.

\begin{tabular}{|c|c|c|c|c|c|}
\hline Feedstock & & Solvent & & Liquefaction rate $(\%)$ & Ref. \\
\hline & Simple olv & $\mathrm{COlc}$ & Ethylene glycol & 85 & [20] \\
\hline & Simpie gi & Cols & Propylene glycol & 99 & \\
\hline Poplar sawdust & & & Diethylene glycol & 63 & \\
\hline & $\begin{array}{l}\text { Higher ana } \\
\text { with gly }\end{array}$ & $\begin{array}{l}\text { ogues } \\
\text { ols }\end{array}$ & Dipropylene glycol & 62 & \\
\hline & & & Polyethylene glycol & 69 & \\
\hline & & & Butanol & $10-12.5$ & {$[31]$} \\
\hline & & & Alcohol & $12.5-15$ & \\
\hline Whont strour alloli lionin & & & Glycerol & About17.5 & \\
\hline W neat straw alkall ngnin & & & Propanol & About 20 & \\
\hline & & & Glycol & $20-22.5$ & \\
\hline & & & Methanol & $25-27.5$ & \\
\hline & & & Methanol & 84.86 & {$[54]$} \\
\hline & & & Ethanol & 84.22 & \\
\hline $\begin{array}{l}\text { Ethanol organosolv lignin } \\
\text { (from bamboo culms) }\end{array}$ & & & Butanol & 49.3 & \\
\hline & & & Ethanediol & 38 & \\
\hline & & & Isopropanol & 27 & \\
\hline & & & Glycerol & 96.71 & [56] \\
\hline & & & PEG400\# & 74.1 & \\
\hline Bamboo (Phyllostachys pubescens) & & & Methanol & 36.47 & \\
\hline & & & Ethanol & 24.97 & \\
\hline & & & Water & 17.74 & \\
\hline & & & Ethylene glycol (EG) & 92.47 & {$[38]$} \\
\hline Corn stover & & & PEG400/glycerin $(4: 1)$ & 92.42 & \\
\hline & & & Glycerin & 72.89 & \\
\hline & & & 0 & 48.5 & [55] \\
\hline Pine (Pinus sn) tree saudust & Concentration of solvents & Concentration of & 25 & 55.4 & \\
\hline 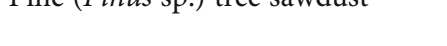 & 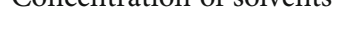 & methanol (\%) & 50 & 62.7 & \\
\hline & & & 100 & 76.3 & \\
\hline & & & Petroleum ether & 23.8 & [16] \\
\hline Peony seeds & & & Hexane & 24.0 & \\
\hline & & & Hexane+ethanol & 24.4 & \\
\hline Fir caurduct & & The mass ratio of & 0.5 & About 82 & [46] \\
\hline 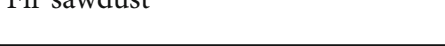 & & PEG400/glycerol & 4.0 & 90.5 & \\
\hline & & & 1.0 & 79.3 & [47] \\
\hline Wood underbrush & & Glycerol to EG ratio & 2.0 & 88.1 & \\
\hline & & & 5.0 & 84.4 & \\
\hline
\end{tabular}

The liquefaction yield of Sargassum polycystum C. Agardh gradually increased when the temperature was between 130 and $170^{\circ} \mathrm{C}$ and then slowly decreased when the temperature increased to $190^{\circ} \mathrm{C}$. Similar to the effect of temperature, the whole reaction was also divided into two stages by reaction time; i.e., the liquefaction yield dramatically increased in the initial $15 \mathrm{~min}$ and tended to keep constant from 15 to $35 \mathrm{~min}$ [28]. Similar results on the relationship between temperature, reaction time, and liquefaction yield of bamboo have also been observed $[58,59]$.

From these results, it can be concluded that liquefaction yield is influenced by interactions existing between temperature and time. The conversion yield of rape straw remark- ably increased and finally reached $87 \%\left(180^{\circ} \mathrm{C}, 10 \mathrm{~min}\right)$ by increasing the liquefaction temperature and prolonging the reaction time [67]. With the temperature at $120^{\circ} \mathrm{C}$ and isopropanol as the solvent, lignin was converted into aromatic compounds (mainly ethanone, 1-(4-hydroxy-3-methoxyphenyl), and ethanone, 1-(4-hydroxy-3, 5-dimethoxy phenyl)) and the yield of the liquid product was $45 \%$. However, from $120^{\circ} \mathrm{C}$ to $180^{\circ} \mathrm{C}$, the liquefaction rate gradually declined to $37 \%$ and the proportion of residues increased [70]. The above analysis indicated that the prevailing reaction temperature for most lignocellulosic biomass except for lignin was in the range of $150-180^{\circ} \mathrm{C}$ depending on the biomass type and reagents used and the preferable time was less than $1 \mathrm{~h}$. Further 

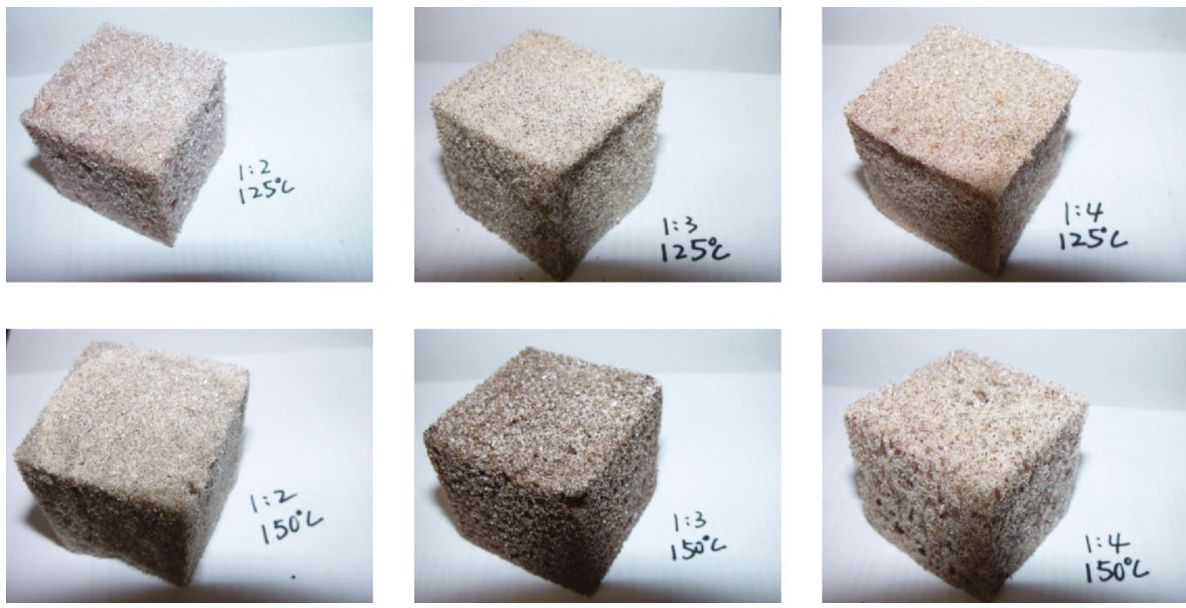

FIGURE 2: Photographs of polyurethane foams prepared from microwave-liquefied bagasse [60].

increases in temperature or prolonging the reaction time may result in a decrease in conversion yield and recondensation of the already decomposed fragments.

5.2. Microwave Power. As microwave power increases, the heating rate of the liquefaction system increases. With the orthogonal experiment (refers to an approach to analyzing a representative test site to achieve process optimization) [71] on microwave liquefaction of corn stover, $\mathrm{Li}$ et al. [39] found that microwave power was the most influential factor. Guo et al. [28] reported that with increasing microwave power from $200 \mathrm{~W}$ to $400 \mathrm{~W}$, the liquefaction yield gradually increased but the liquefaction yield clearly decreased when the power was increased to $600 \mathrm{~W}$. Chai and Tao [40] found that the residue content of liquefied bamboo first decreased and then increased as the microwave power increased. The minimum residue content of bamboo was as low as $3.4 \%$ when the maximum microwave power was $500 \mathrm{~W}$. The yield of bio-oil from the liquefaction of Ulva prolifera increased as the microwave power was 200-600 W, while the yield decreased as the microwave power was $600-800 \mathrm{~W}$. The decrease of the liquefaction yield with high microwave power may be because bio-oils could easily undergo recondensation [51].

\section{Microwave Liquefaction Products and Utilization}

Biopolymers are commonly considered as renewable, biodegradable, and ecofriendly materials. They can be obtained completely or partially from renewable resources and synthesized like traditional plastics [72]. Compared to polymers based on petroleum, biopolymers derived from renewable resources avoid fossil fuels and the relative amount of the net carbon released is much smaller [73].

For microwave liquefaction, the liquefaction products usually can be divided into two portions, the liquid and the solid parts. Generally, the liquefaction reaction mixtures will be filtered through filter paper, and solid parts are retained on the filter paper, and liquid parts are filtered through the filter paper. The chemical composition of the two parts is different.
By replacing the raw materials with liquefied products, it can not only increase the biodegradability of bioproducts but also lower the cost of production. There are different kinds of biobased polymer products from microwave liquefaction, which can be applied in many fields, such as biobased polyurethane foams, biobased adhesives, and cellulosereinforced materials.

6.1. Integrated Utilization of Liquefied Liquid. In most studies, the liquid products from the microwave liquefaction of lignocellulosic biomass were analyzed and applied to polyurethane foam (PUR) and phenol resins depending on the solvents used. Various lignocellulosic biomass types such as poplar, southern pine, bamboo, bagasse, agricultural residues, and lignin have been microwave liquefied in alcohol solvents to produce PU foams. As shown in Figure 2, under different liquefaction conditions (the mass ratio of bagasse flour and biocomponent polyhydric alcohol was $1: 2,1: 3$, and $1: 4$ and the temperature was $125^{\circ} \mathrm{C}$ and $150^{\circ} \mathrm{C}$ ), all the synthesized PU foams were of rigid type and the foam was darker in color with the addition of the liquefied bagasse $[49,60,74-80]$. The properties of the fabricated biobased foams from microwave-liquefied products were largely dependent on the biomass type, heating methods, and liquefaction conditions. Research results with corn stover revealed that the PU foams with the addition of microwave liquefaction materials had favorable biodegradability but poor thermal stability compared to those synthesized with conventional liquefaction. The poor thermal stability is mainly because the molecular weight of the microwave liquefaction product of corn stover is lower than that of the conventional liquefied product, resulting in a decrease in the degree of crosslinking of the synthesized polyurethane [26]. The application of the proper amount (less than 10\%) of lignin fractionated from the microwave-assisted liquefied switchgrass into the PU matrix could improve the performances of PU foams in the apparent density, mechanical strength, and thermal stability [79]. By adding 20\% biopolyol from microwave-liquefied rape straw, the biofoam cell diameter decreased by $90 \%$ compared with the PU without biopolyol from rape straw and the foam cell became more 
homogenous and finer, and the PU foams exhibited extremely low thermal conductivity and excellent mechanical strength. The further addition of $4 \%$ cellulose nanocrystals (CNCs) increased Young's modulus and compressive stress by $590 \%$ and $150 \%$, respectively [80]. The use of liquefaction biopolyol with the presence of solid residue could enhance the thermal stability of the biofoams [81]. By adding the liquefied products of bagasse from high reaction temperature, the PU foams possessed better physical and mechanical performance compared with those prepared with liquefied products from low temperature. High polyhydric alcohol concentration in the liquefied bagasse resulted in higher thermal stability of the biofoams [60]. In the preparation of the rigid PU foams from microwave-liquefied lignin products without any pretreatment, by increasing the $[\mathrm{NOC}] /[\mathrm{OH}]$ ratio from 0.6 to 1.0 , the compressive strength of the foams increased [78]. By increasing the biopolyol proportion from microwave-liquefied lignin (from 25\% to 50\%), the apparent density, compressive strength, and thermal stability of the obtained biobased foams all increased [49]. Research also indicated that the lignin derivatives from the microwave-liquefied bamboo biopolyols could increase the density and thermal stability of the biofoams [74].

In addition to the application of the liquefied liquid in the preparation of PU foams, adhesives and polyether polyols have also been made from biopolyols from microwave liquefaction. Under the presence of $\mathrm{MgO}$, phenolic compounds were obtained from microwave-assisted liquefaction of bamboo and were successfully applied to synthesizing fast-curing phenol-formaldehyde resins [82]. Biomass-based polyether polyols were prepared from the microwave-liquefied poplar products with double metal cyanide MMC as a catalyst [77]. The main compositions of bio-oil from microwave liquefaction are listed in Table 2. As shown in Table 2, bio-oil from different feedstocks showed different compositions. Under different liquefaction conditions, main compositions from the same feedstock are also different. Bio-oil from cotton stalk, rape straw, S. polycystum C. Agardh, Ulva prolifera, and Nannochloropsis oceanica has similar composition with different content.

6.2. Fractionation and Utilization of Liquefied Products. The compositions of the microwave-liquefied products were complex due to the complex composition of the lignocellulosic biomass. Fractionation of the liquefied products was an efficient method to realize the high value of the liquefied products and expand their utilization. $\mathrm{Xu}$ et al. [57] successfully separated the liquid products from the microwave-liquefied lignocellulosic biomass into the phenolic rich fraction (phenolic compounds) and the sugar derivative fraction (biopolyols) via a simple method. With microwave-assisted liquefaction of bamboo, aromatic and monosaccharide derivatives were also successfully obtained with stepwise precipitation and extraction [83]. The content of glycoside compounds in the monosaccharides was 92\%, and the content of the phenolic compounds in the aromatic fraction was approximately $82 \%$ [84]. The water-soluble fraction of the liquefied corn stover was extracted with hexane, chloroform, diethyl ether, and ethyl acetate. The results revealed that the content of levulinic acid isopropyl ester was higher in the chloroform and ethyl acetate, while the hexane and ether extract had a lower levulinic acid isopropyl ester content [85]. Lignin recovered from the microwave liquefaction of lignocellulosic biomass (moso bamboo, Chinese tallow tree wood, switchgrass, and pine wood) in a binary glycerol/methanol solvent retained the core structure of lignin and had high solubility in common solvents. The addition of the fractionated lignin from microwave liquefaction into a polylactide (PLA) matrix improved the tensile properties of PLA-lignin composites, and the PLA films with low lignin content possessed good UV light-resistant properties [86]. Detoxified cellulosic components and lignin fractions were successfully fractionated from microwave-liquefied decommissioned chromate copper arsenate- (CCA-) treated wood poles, and the metals were almost completely distributed in the spent liquor [87].

6.3. Characterization and Utilization of Liquefied Residues. Research on microwave liquefaction of lignocellulosic biomass has also focused on process optimization and utilizations of the liquid products. In order to make full use of biomass to achieve close-loop utilization of the resource via microwave liquefaction, research on the characterization and potential utilization of liquefied residues was performed in several studies. Morphology, chemical structure, and thermal stability of the microwave-liquefied residues were thoroughly investigated to obtain a better understanding of the microwave liquefaction behaviors of biomass $[43,55,88]$. Further research found that the microwaveliquefied bamboo residues still retained the cell wall structure and tracing cellulose, and pure white cellulose fibers could be extracted from the residues with a mild bleaching process. Further treatment of the cellulose yielded nanofibrillated cellulosic fibers with lengths greater than $550 \mathrm{~nm}$ (Figure 3) [50, 89, 90].

\section{Liquefaction Mechanism on Microwave Liquefaction}

Previous research on the mechanism of microwave liquefaction is limited. In one study, the chemical reaction mechanism on microwave liquefaction in methanol was proposed [57]. Xie et al. proposed that selective liquefaction of bamboo cell wall components existed during microwave liquefaction based on the findings that lignin and extractives were more easily decomposed than cellulose, and the proposed selective liquefaction process has been used to produce high value cellulose nanofibers (Figure 4) [89, 91]. However, previous research did not provide any evidence to indicate if microwave energy affected the chemical reactions or selective liquefaction of cell wall components.

\section{Conclusions}

This report gives a review on recent research on microwaveassisted liquefaction of lignocellulosic biomass. Microwave 


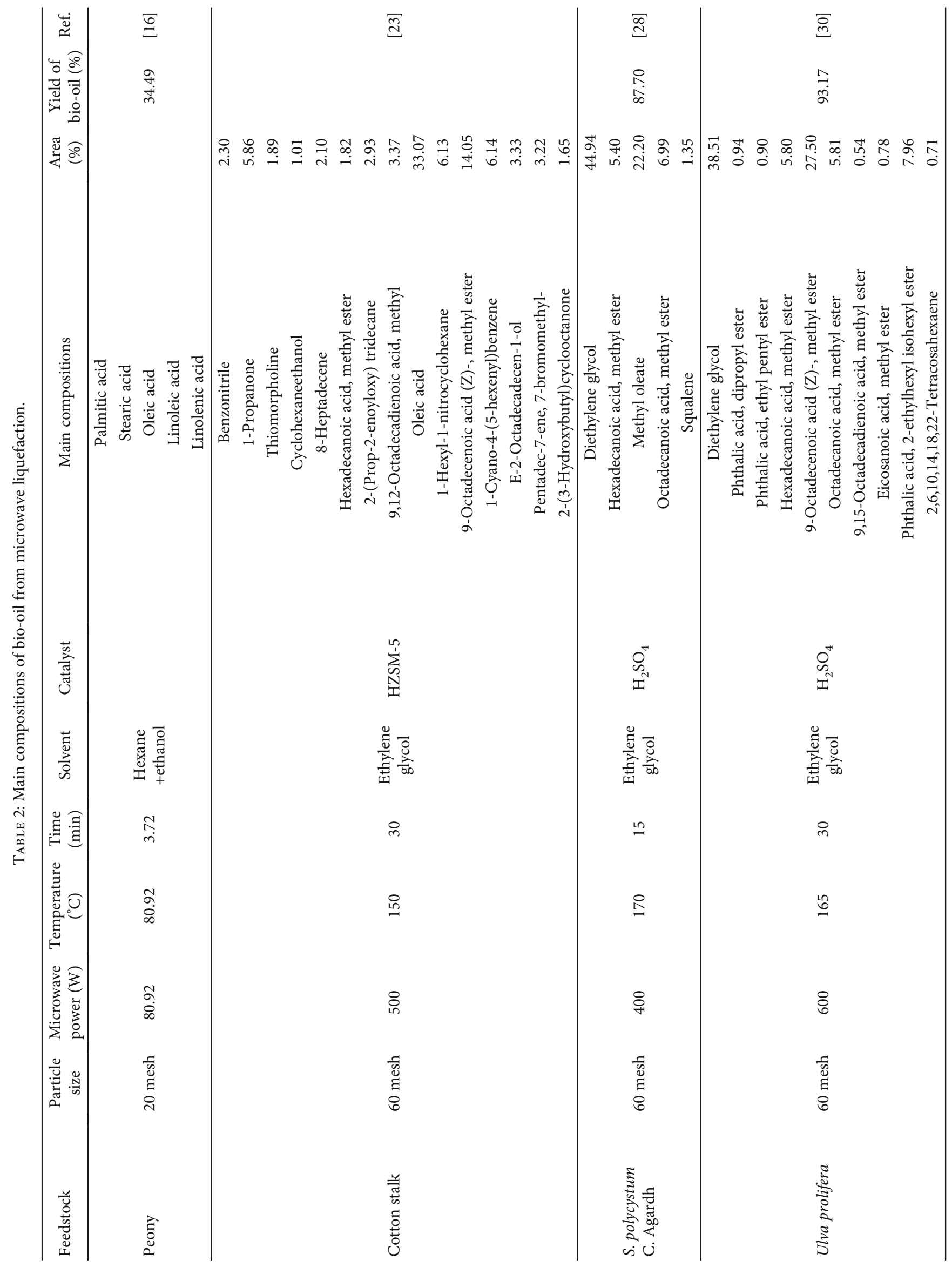




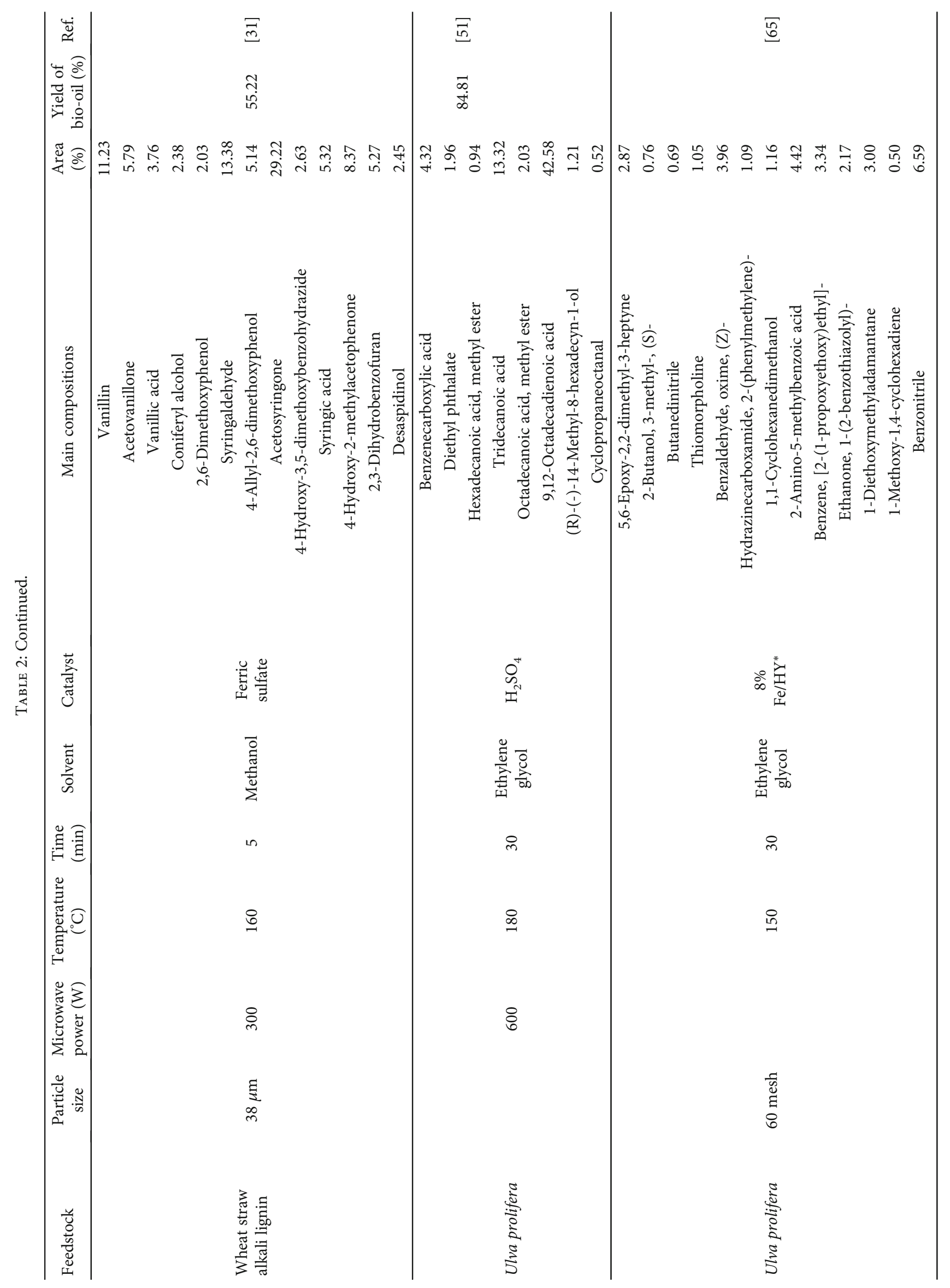




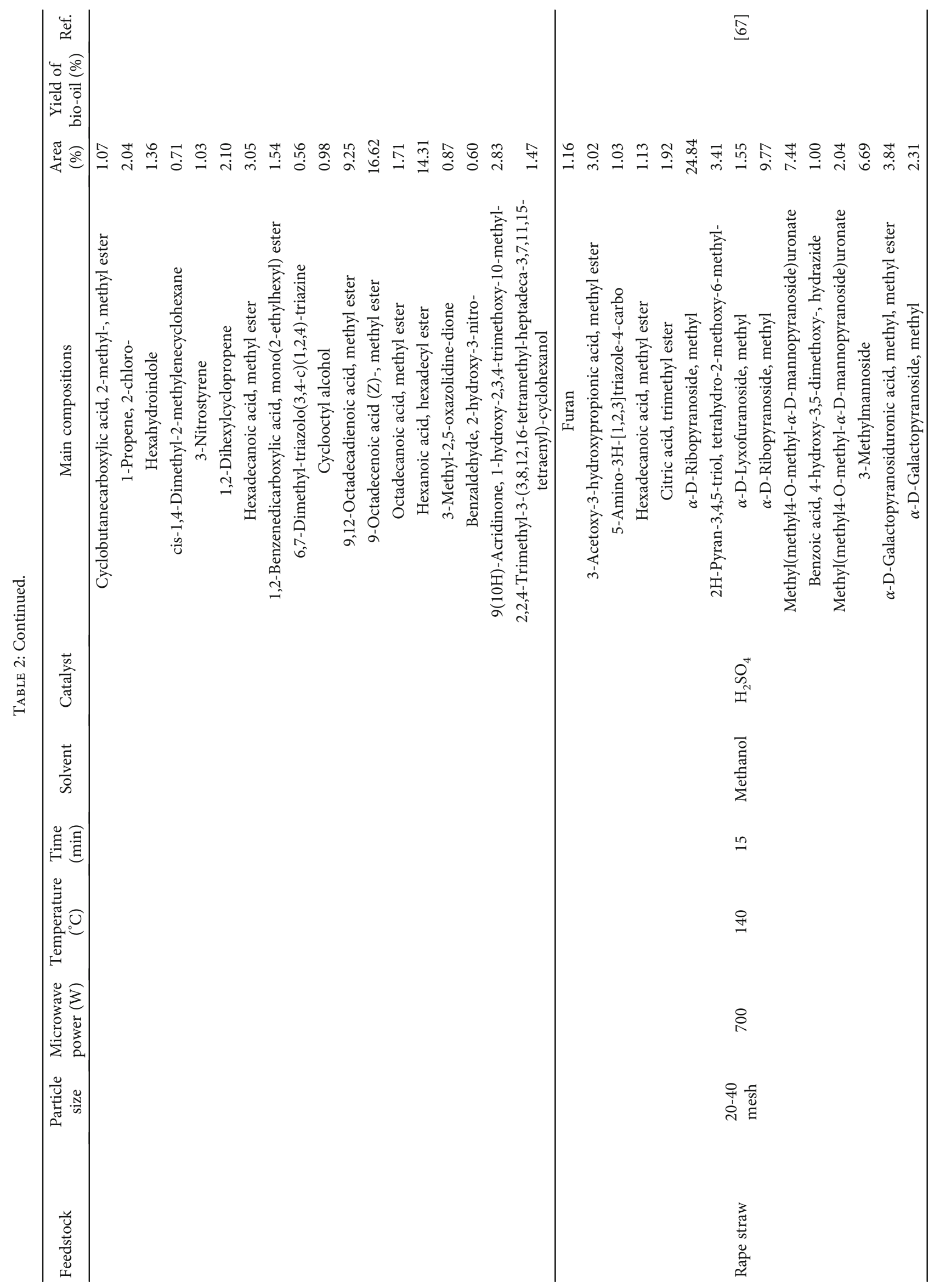




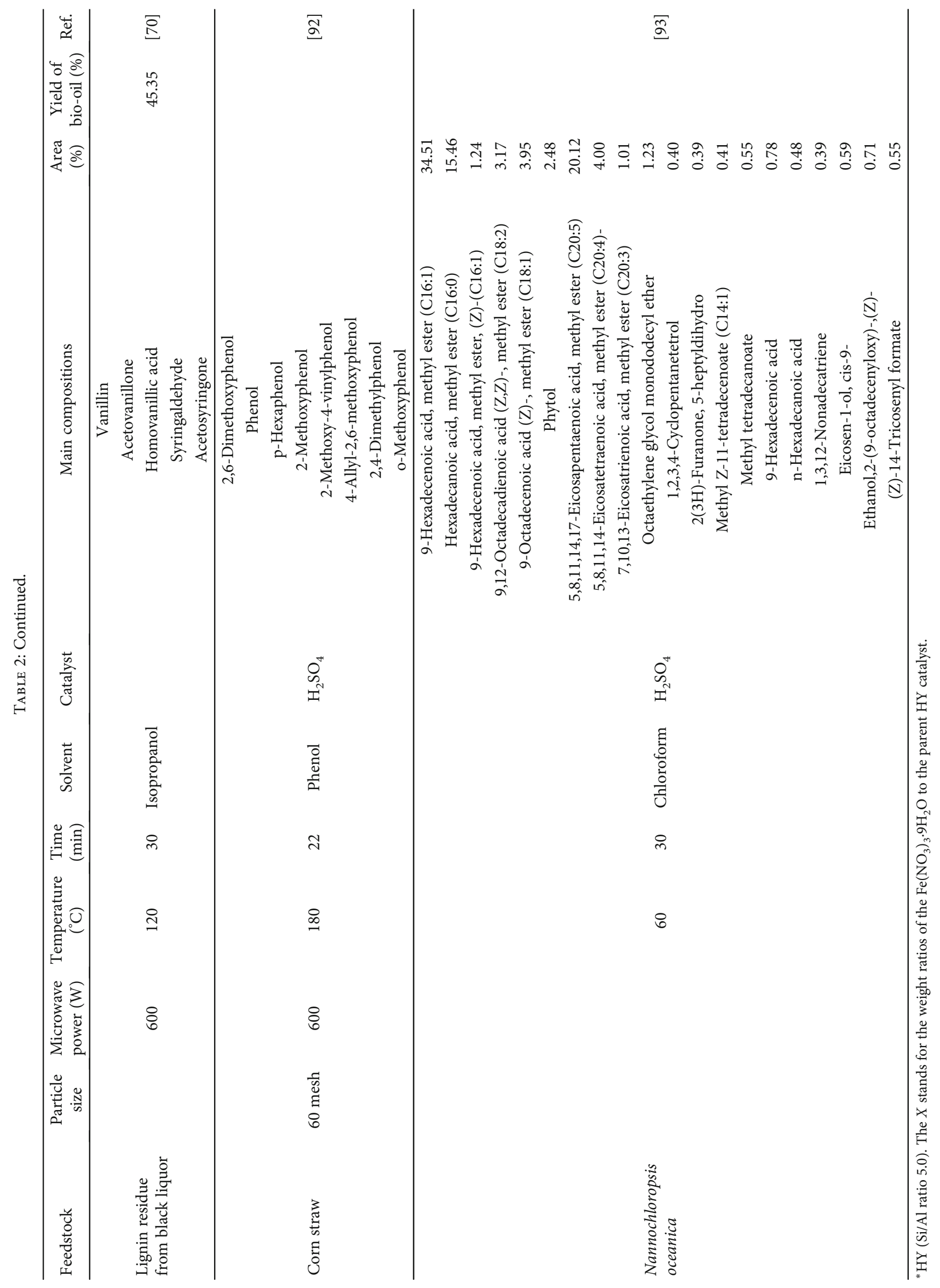




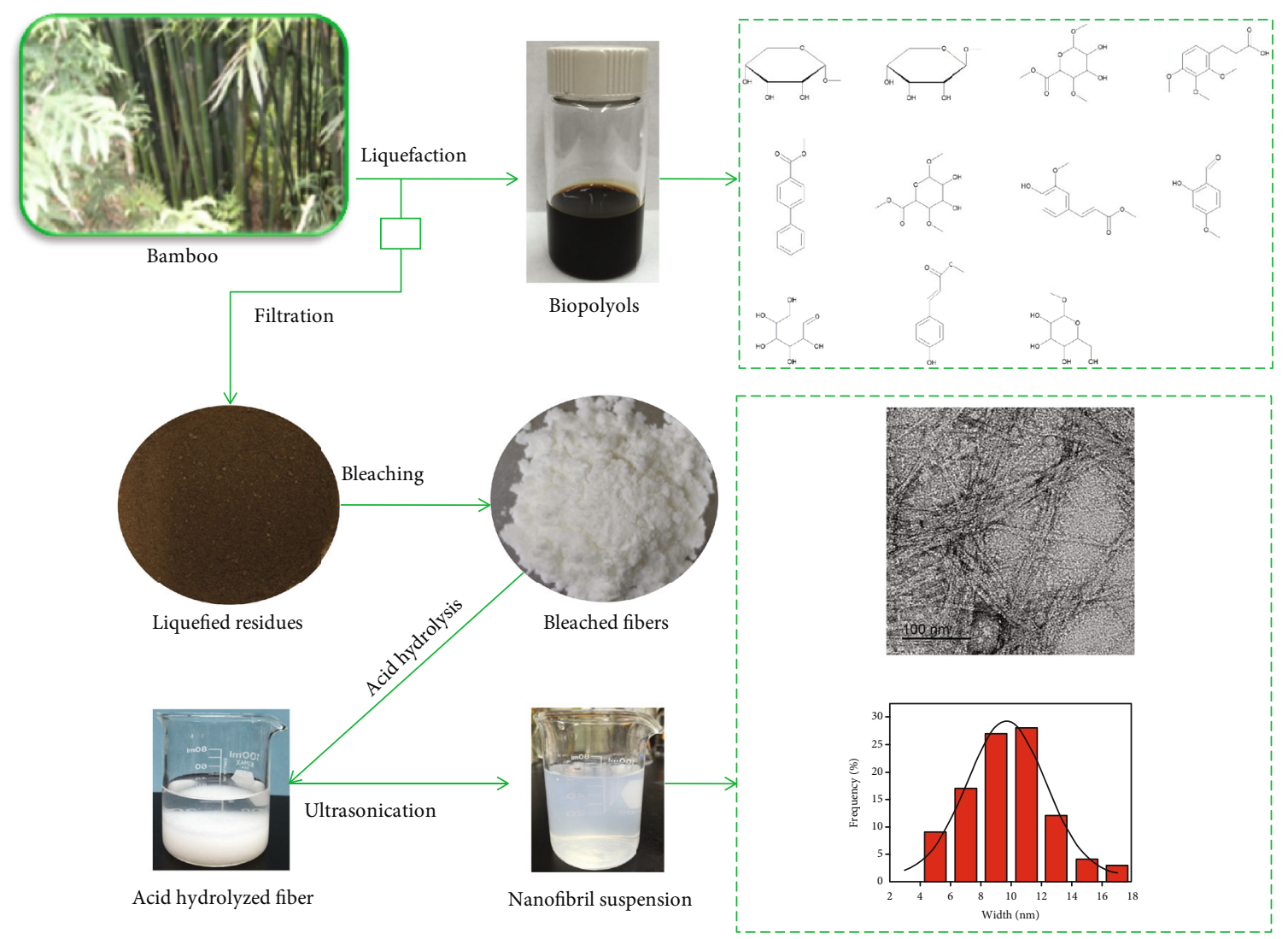

Figure 3: Potential application of microwave-liquefied bamboo residues for the extraction of cellulose nanofibers based on the residue characterization [50].

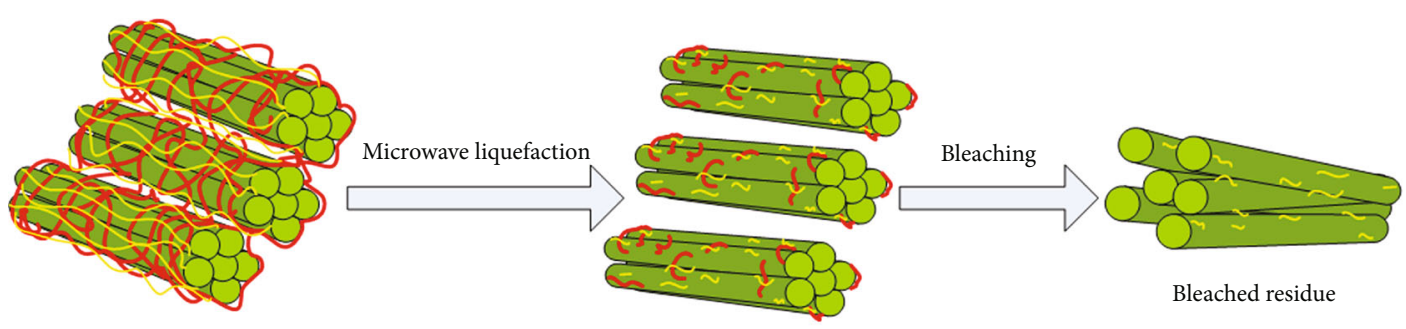

Raw bamboo particles

Microwave-liquefied residue

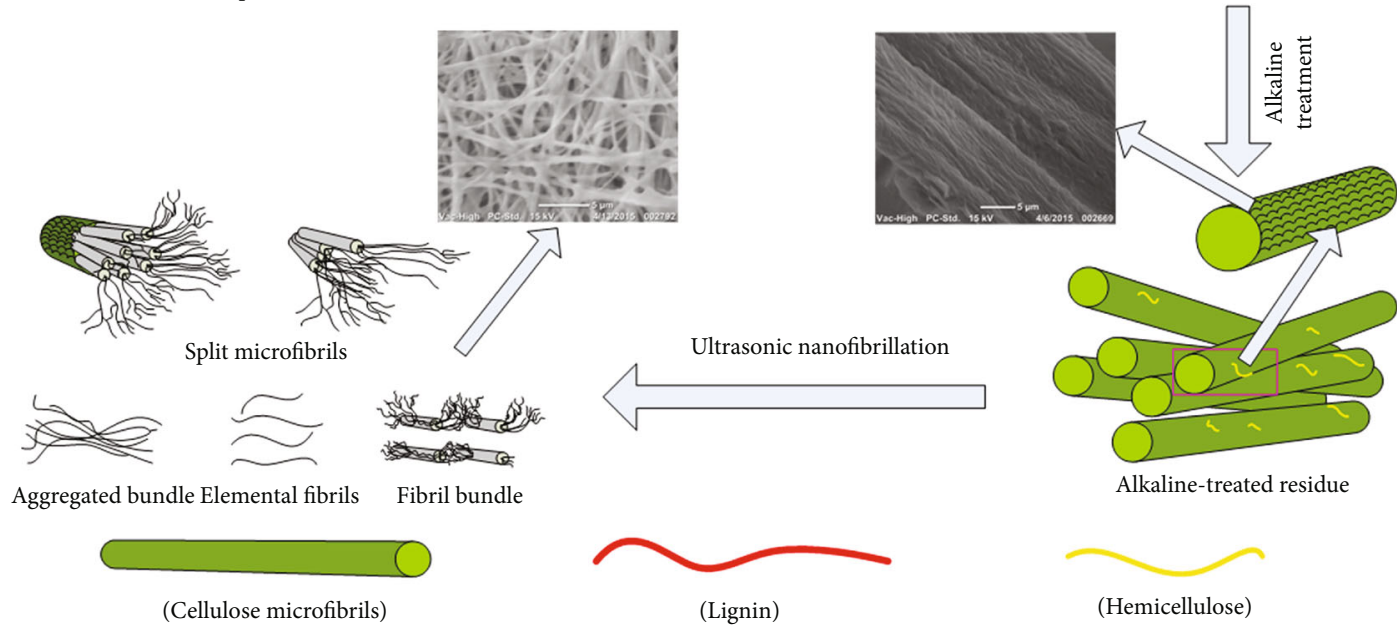

FIGURE 4: Proposed mechanism on the preparation of nanocellulose using microwave selective liquefaction assisted with chemical treatments [89]. 
liquefaction of lignocellulosic biomass was proven to be an efficient and environmentally friendly method to produce biochemicals and biomaterials. The obtained products exhibited comparable properties to commercially available biochemicals and bioproducts and thus could likely be applied in the bioproduct industries. Possible further work is still needed regarding scalable production and affecting factors of microwave liquefaction.

(1) All the reviewed previous research data on microwave liquefaction of lignocellulosic biomass was collected using small laboratory-scale microwave reactors. Pilot-scale experiments on the microwave liquefaction and the product utilizations should be considered and conducted in the near further

(2) Microwave dielectric heating depends on the ability of a material to absorb microwave energy and convert it into heat. A hypothesis may be that the absorbance of the components of lignocellulosic biomass may differ from each other, which may decide the decomposition order of each component and influence the chemical reactions of the components during the liquefaction process. However, further research is needed in this regard

\section{Conflicts of Interest}

The authors declare no conflicts of interest regarding the publication of this paper.

\section{Acknowledgments}

The work is supported by the Science and Technology Innovation Foundation for College Students at Sichuan Agricultural University.

\section{References}

[1] A. L. Ahmad, N. H. M. Yasin, C. J. C. Derek, and J. K. Lim, "Microalgae as a sustainable energy source for biodiesel production: a review," Renewable and Sustainable Energy Reviews, vol. 15, no. 1, pp. 584-593, 2011.

[2] J. Asomaning, S. Haupt, M. Chae, and D. C. Bressler, "Recent developments in microwave-assisted thermal conversion of biomass for fuels and chemicals," Renewable and Sustainable Energy Reviews, vol. 92, pp. 642-657, 2018.

[3] F. Motasemi and M. T. Afzal, "A review on the microwaveassisted pyrolysis technique," Renewable and Sustainable Energy Reviews, vol. 28, no. 8, pp. 317-330, 2013.

[4] B. B. Zhang, "Assessment of raw material supply capability and energy potential of biomass resources in China," $\mathrm{PhD}$ thesis, China Agricultural University, Beijing, China, 28th edition, 2018.

[5] D. Kim, "Physico-chemical conversion of lignocellulose: inhibitor effects and detoxification strategies: a mini review," Molecules, vol. 23, no. 2, p. 309, 2018.

[6] Y. X. Liu and G. J. Zhao, Wood science, China Forestry Press, Beijing, China, 2012.

[7] H. B. Goyal, D. Seal, and R. C. Saxena, "Bio-fuels from thermochemical conversion of renewable resources: a review,"
Renewable and Sustainable Energy Reviews, vol. 12, no. 2, pp. 504-517, 2008.

[8] G. Li, C. Hse, and T. Qin, "Wood liquefaction with phenol by microwave heating and FTIR evaluation," Journal of Forest Research, vol. 26, no. 4, pp. 1043-1048, 2015.

[9] Z. Liu and F.-S. Zhang, "Effects of various solvents on the liquefaction of biomass to produce fuels and chemical feedstocks," Energy Conversion and Management, vol. 49, no. 12, pp. 3498-3504, 2008.

[10] J. Yip, M. Chen, Y. S. Szeto, and S. Yan, “Comparative study of liquefaction process and liquefied products from bamboo using different organic solvents," Bioresource Technology, vol. 100, no. 24, pp. 6674-6678, 2009.

[11] H. J. Huang and X. Z. Yuan, "Recent progress in the direct liquefaction of typical biomass," Progress in Energy and Combustion Science, vol. 49, pp. 59-80, 2015.

[12] N. Wang, C. R. Tian, X. Y. Lin, and J. H. Wang, "Microwaveassisted liquefaction of rice straw," Biomass Chemical Engineering, vol. 47, no. 1, pp. 33-38, 2013.

[13] A. Zlotorzynski, "The application of microwave radiation to analytical and environmental chemistry," Critical Reviews in Analytical Chemistry, vol. 25, no. 1, pp. 43-76, 1995.

[14] D. M. P. Mingos and D. R. Baghurst, "Tilden lecture. Applications of microwave dielectric heating effects to synthetic problems in chemistry," Chemical Society Reviews, vol. 20, no. 1, p. 1, 1991.

[15] C. S. Eskilsson and E. Björklund, "Analytical-scale microwaveassisted extraction," Journal of Chromatography. A, vol. 902, no. 1, pp. 227-250, 2000.

[16] X. Sun, W. Li, J. Li et al., "Process optimisation of microwaveassisted extraction of peony (Paeonia suffruticosa andr.) seed oil using hexane-ethanol mixture and its characterisation," International Journal of Food Science \& Technology, vol. 51, no. 12, pp. 2663-2673, 2016.

[17] P. Lahijani, Z. A. Zainal, A. R. Mohamed, and M. Mohammadi, "Microwave-enhanced $\mathrm{CO}_{2}$ gasification of oil palm shell char," Bioresource Technology, vol. 158, pp. 193-200, 2014.

[18] P. Shuttleworth, V. Budarin, M. Gronnow, J. H. Clark, and R. Luque, "Low temperature microwave-assisted vs conventional pyrolysis of various biomass feedstocks," Journal of Natural Gas Chemistry, vol. 21, no. 3, pp. 270-274, 2012.

[19] A. Krzan and M. Kunaver, "Microwave heating in wood liquefaction," Journal of Applied Polymer Science, vol. 101, no. 2, pp. 1051-1056, 2006.

[20] A. Krzan and E. Zagar, "Microwave driven wood liquefaction with glycols," Bioresource Technology, vol. 100, no. 12, pp. 3143-3146, 2009.

[21] W. Xiao, L. Han, and Y. Zhao, "Comparative study of conventional and microwave-assisted liquefaction of corn stover in ethylene glycol," Industrial Crops and Products, vol. 34, no. 3, pp. 1602-1606, 2011.

[22] G. Y. Li, X. C. Zhu, X. W. Zou, and T. F. Qin, "Microwaveassisted liquefaction of five types of biomass in polyhydric alcohols," Chemistry and Industry of Forest Products, vol. 35, no. 1, pp. 107-112, 2015.

[23] X. Kong, X. Li, S. Wu, X. Zhang, and J. Liu, "Efficient conversion of cotton stalks over a Fe modified HZSM-5 catalyst under microwave irradiation," RSC Advances, vol. 6, no. 34, pp. 28532-28537, 2016. 
[24] Z. D. Liao, J. F. Lan, J. R. Ruan, and X. D. Li, “Optimization of bagasse ethylene glycol liquefaction technology by microwave pretreatment," Hubei Agricultural Sciences, vol. 52, no. 7, 2013.

[25] W. Xiao, W. Niu, F. Yi, X. Liu, and L. Han, "Influence of crop residue types on microwave-assisted liquefaction performance and products," Energy \& Fuels, vol. 27, no. 6, pp. 3204-3208, 2013.

[26] W. H. Xiao, Z. N. Li, W. J. Niu, and L. J. Han, "Biodegradable polyurethane foam with liquefied product from corn Stover," Transactions of the Chinese Society for Agricultural Machinery, vol. 44, no. 3, pp. 124-128, 2013.

[27] A. Sequeiros, L. Serrano, R. Briones, and J. Labidi, "Lignin liquefaction under microwave heating," Journal of Applied Polymer Science, vol. 130, no. 5, pp. 3292-3298, 2013.

[28] J. Guo, Y. Zhuang, L. Chen, J. Liu, D. Li, and N. Ye, "Process optimization for microwave-assisted direct liquefaction of Sargassum polycystum C. Agardh using response surface methodology," Bioresource Technology, vol. 120, pp. 19-25, 2012.

[29] A. B. Ross, "Hydrothermal microwave processing of microalgae as a pre-treatment and extraction technique for bio-fuels and bio-products," Bioresource Technology, vol. 136, no. 3, pp. 188-195, 2013.

[30] J. Liu, Y. Zhuang, Y. Li et al., "Optimizing the conditions for the microwave-assisted direct liquefaction of Ulva prolifera for bio-oil production using response surface methodology," Energy, vol. 60, pp. 69-76, 2013.

[31] X. P. Ouyang, X. Z. Huang, and X. Q. Qiu, "Liquefaction of wheat straw alkali lignin under microwave irradiation," Journal of Fuel Chemistry and Technology, vol. 42, no. 10, pp. 1212-1217, 2014.

[32] Z. Q. Zheng, Y. Liu, D. Li, L. Wang, B. Adhikari, and X. D. Chen, "Microwave-driven sugar beet pulp liquefaction in polyhydric alcohols," International Journal of Food Engineering, vol. 13, no. 7, 2017.

[33] U. A. Amran, S. Zakaria, C. H. Chia, Z. Fang, and M. Z. Masli, "Production of Liquefied Oil Palm Empty Fruit Bunch Based Polyols via Microwave Heating," Energy \& Fuels, vol. 31, no. 10, pp. 10975-10982, 2017.

[34] L. Zhou, V. Budarin, J. Fan, R. Sloan, and D. Macquarrie, "Efficient method of lignin isolation using microwave-assisted acidolysis and characterization of the residual lignin," ACS Sustainable Chemistry \& Engineering, vol. 5, no. 5, pp. 37683774, 2017.

[35] W. Zhou, W. X. Fu, and Y. C. Zhang, "Liquefaction of banana pseudo-stem and preparation of polyurethane adhesive from liquefied products," Journal of Wuhan University of Technology-Materials Science Edition, vol. 6, pp. 1437-1443, 2018.

[36] J. Wu, S. Y. Xu, F. R. Meng, J. Zhang, Y. C. Zhang, and D. Wang, "Microwave assisted liquefaction of coconut fiber," Biomass Chemical Engineering, vol. 52, no. 3, pp. 40-44, 2018.

[37] N. Soto-Reyes, A. López-Malo, R. Rojas-Laguna, J. A. GómezSalazar, and M. E. Sosa-Morales, "Effects of microwaveassisted hot water treatments designed against Mexican fruit fly (Anastrepha ludens) on grapefruit (Citrus paradisi) quality," Journal of the Science of Food and Agriculture, vol. 98, no. 10, pp. 3659-3666, 2018.

[38] W. H. Xiao, X. M. Zhang, X. Wang, W. J. Niu, and L. J. Han, "Rapid liquefaction of corn stover with microwave heating," Bioresources, vol. 10, no. 3, pp. 4038-4047, 2015.
[39] X. Y. Li, X. Q. Li, X. X. Duan, W. Qi, J. Y. Shi, and Y. Z. Lei, "Research on flexible microwave assisted liquefaction and characteristics of corn straw," Acta Energiae Solaris Sinica, vol. 38, no. 5, pp. 1453-1458, 2017.

[40] X. Chai and L. Tao, "The bamboo powder microwave liquefied and preparation of biomass polyol," Journal of Cellular Science and Technology, vol. 22, no. 1, pp. 1-4, 2014.

[41] S. Q. Qian, S. Wen, Z. D. Liao, L. Yu, L. F. Yu, and Q. L. Chen, "Optimizing liquefaction technology of bamboo powder ethylene glycol with microwave," Hubei Agricultural Sciences, vol. 54, no. 5, pp. 1166-1168, 2015.

[42] J. Q. Qi, J. L. Xie, C. Y. Hse, and T. F. Shupe, "Analysis of Phyllostachys pubescens bamboo residues for liquefaction: chemical components, infrared spectroscopy, and thermogravimetry," BioResources, vol. 8, no. 4, pp. 5644-5654, 2013.

[43] J. Xie, X. Huang, J. Qi, C.-Y. Hse, and T. F. Shupe, "Effect of Anatomical Characteristics and Chemical Components on Microwave-assisted Liquefaction of Bamboo Wastes," BioResources, vol. 9, no. 1, 2013.

[44] G. D. Feng, Y. H. Zhou, X. X. Guo, and L. H. Hu, "Optimization of wood liquefaction using microwave heating with response surface methodology," Journal of Cellular Science and Technology, vol. 17, no. 4, pp. 21-30, 2009.

[45] G. Y. Li, X. C. Zhu, X. W. Zou, Q. Xiang, and Y. C. He, "Rapid wood liquefaction with phenol by microwave heating and product characterization," Scientia Silvae Sinica, vol. 50, no. 11, pp. 115-121, 2014.

[46] Z. Lu, Z. Wu, L. Fan et al., "Rapid and solvent-saving liquefaction of woody biomass using microwave-ultrasonic assisted technology," Bioresource Technology, vol. 199, pp. 423-426, 2015.

[47] X. Y. Huang, J. Q. Qi, F. Cornelis, J. L. Xie, and Y. Z. Chen, "Biobased polyurethane foam insulation from microwave liquefaction of woody underbrush," Bioresources, vol. 12, no. 4, pp. 8160-8179, 2017.

[48] S. Hassanzadeh, N. Aminlashgari, and M. Hakkarainen, "Microwave-assisted recycling of waste paper to green platform chemicals and carbon nanospheres," ACS Sustainable Chemistry \& Engineering, vol. 3, no. 1, pp. 177-185, 2015.

[49] K. Gosz, P. Kosmela, A. Hejna, G. Gajowiec, and Ł. Piszczyk, "Biopolyols obtained via microwave-assisted liquefaction of lignin: structure, rheological, physical and thermal properties," Wood Science and Technology, vol. 52, no. 3, pp. 599-617, 2018.

[50] J. Xie, C.-Y. Hse, C. Li et al., "Characterization of microwave liquefied bamboo residue and its potential use in the generation of nanofibrillated cellulosic fiber," ACS Sustainable Chemistry \& Engineering, vol. 4, no. 6, pp. 3477-3485, 2016.

[51] Y. Zhuang, J. Guo, L. Chen, D. Li, J. Liu, and N. Ye, "Microwave-assisted direct liquefaction of Ulva prolifera for bio-oil production by acid catalysis," Bioresource Technology, vol. 116, pp. 133-139, 2012.

[52] Y. Wang, H. Wang, H. Lin et al., "Effects of solvents and catalysts in liquefaction of pinewood sawdust for the production of bio-oils," Biomass and Bioenergy, vol. 59, pp. 158-167, 2013.

[53] A. Kržan and E. Žagar, "Microwave driven wood liquefaction with glycols," Bioresource Technology, vol. 99, no. 12, pp. 3143-3146, 2009.

[54] D. Duan, Y. Wang, R. Ruan et al., "Comparative study on various alcohols solvolysis of organosolv lignin using microwave 
energy: physicochemical and morphological properties," Chemical Engineering and Processing, vol. 126, pp. 38-44, 2018.

[55] J. Xie, C.-Y. Hse, T. F. Shupe, and T. Hu, "Influence of solvent type on microwave-assisted liquefaction of bamboo," European Journal of Wood and Wood Products, vol. 74, no. 2, pp. 249-254, 2016.

[56] J. Xu, J. Jiang, C. Y. Hse, and T. F. Shupe, "Effect of methanol on the liquefaction reaction of biomass in hot compressed water under microwave energy," Energy \& Fuels, vol. 27, no. 8, pp. 4791-4795, 2013.

[57] J. Xu, J. Jiang, C. Hse, and T. F. Shupe, "Renewable chemical feedstocks from integrated liquefaction processing of lignocellulosic materials using microwave energy," Green Chemistry, vol. 14, no. 10, pp. 2821-2830, 2012.

[58] J. L. Xie, C. Y. Hse, T. F. Shupe, J. Q. Qi, and H. Pan, "Liquefaction behaviors of bamboo residues in a glycerol-based solvent using microwave energy," Journal of Applied Polymer Science, vol. 131, no. 9, 2014.

[59] J. Xie, J. Qi, C. Hse, and T. F. Shupe, "Optimization for microwave-assisted direct liquefaction of bamboo residue in glycerol/methanol mixtures," Journal of Forest Research, vol. 26, no. 1, pp. 261-265, 2015.

[60] J. L. Xie, X. L. Zhai, C. Hse, T. Shupe, and H. Pan, "Polyols from microwave liquefied bagasse and its application to rigid polyurethane foam," Maternité, vol. 8, no. 12, pp. 8496-8509, 2015.

[61] M. Tayier, D. Duan, Y. Zhao, R. Ruan, Y. Wang, and Y. Liu, "Catalytic effects of various acids on microwave-assisted depolymerization of organosolv lignin," Bioresources, vol. 13, no. 1, pp. 412-424, 2017.

[62] X. Ouyang, G. Zhu, X. Huang, and X. Qiu, "Microwave assisted liquefaction of wheat straw alkali lignin for the production of monophenolic compounds," Journal of Energy Chemistry, vol. 24, no. 1, pp. 72-76, 2015.

[63] S. Hassanzadeh, N. Aminlashgari, and M. Hakkarainen, "Chemo-selective high yield microwave assisted reaction turns cellulose to green chemicals," Carbohydrate Polymers, vol. 112, pp. 448-457, 2014.

[64] X. Kong, S. Wu, X. Li, and J. Liu, "Microwave-assisted liquefaction of Ulva prolifera over $\mathrm{Fe}_{2} \mathrm{O}_{3}$-modified HY catalyst," Journal of Energy Engineering, vol. 144, no. 1, p. 04017071, 2018.

[65] S. H. F. da Silva, P. S. B. dos Santos, D. Thomas da Silva, R. Briones, D. A. Gatto, and J. Labidi, "Kraft lignin-based polyols by microwave: optimizing reaction conditions," Journal of Wood Chemistry and Technology, vol. 37, no. 5, pp. 343-358, 2017.

[66] X. Chai, "Technology optimization of bamboo powder liquefaction with phenol under microwave heating conditions," Journal of Southwest Forestry University, vol. 34, no. 2, pp. 108-110, 2014.

[67] X. Y. Huang, F. Li, J. L. Xie et al., "Microwave-assisted liquefaction of rape straw for the production of bio-oils," BioResources, vol. 12, no. 1, pp. 1968-1981, 2017.

[68] D. Duan, Y. Zhao, L. Fan et al., "Low-power microwave radiation-assisted depolymerization of ethanol organosolv lignin in ethanol/formic acid mixtures," BioResources, vol. 12, no. 3, 2017.

[69] K. Wang, K. H. Kim, and R. C. Brown, "Catalytic pyrolysis of individual components of lignocellulosic biomass," Green Chemistry, vol. 16, no. 2, pp. 727-735, 2014.
[70] Q. Liu, P. Li, N. Liu, and D. Shen, "Lignin depolymerization to aromatic monomers and oligomers in isopropanol assisted by microwave heating," Polymer Degradation and Stability, vol. 135, pp. 54-60, 2017.

[71] R. J. Liu, Y. W. Zhang, C. W. Wen, and J. Tang, "Study on the design and analysis methods of orthogonal experiment," Experimental Technology and Management, vol. 27, no. 9, pp. 52-55, 2010.

[72] T. A. Hottle, M. M. Bilec, and A. E. Landis, "Sustainability assessments of bio-based polymers," Polymer Degradation and Stability, vol. 98, no. 9, pp. 1898-1907, 2013.

[73] S. A. Miller, A. E. Landis, and T. L. Theis, "Feature: environmental trade-offs of biobased production," Environmental Science \& Technology, vol. 41, no. 15, pp. 5176-5182, 2007.

[74] H. Pan, Z. Zheng, and C. Y. Hse, "Microwave-assisted liquefaction of wood with polyhydric alcohols and its application in preparation of polyurethane (PU) foams," European Journal of Wood and Wood Products, vol. 70, no. 4, pp. 461-470, 2012.

[75] J. L. Xie, J. Q. Qi, C. Y. Hse, and T. F. Shupe, "Effect of lignin derivatives in the bio-polyols from microwave liquefied bamboo on the properties of polyurethane foams," BioResources, vol. 9, no. 1, pp. 578-588, 2014.

[76] J. Xu, J. Jiang, C.-Y. Hse, and T. F. Shupe, "Preparation of polyurethane foams using fractionated products in liquefied wood," Journal of Applied Polymer Science, vol. 131, no. 7, 2014.

[77] X. C. Zhu, G. Y. Li, and T. F. Qin, "Polyhydric alcohol liquefaction process of poplar using microwave heating and product properties," China Wood Industry, vol. 28, no. 1, pp. 18-22, 2014.

[78] B. L. Xue, J. L. Wen, and R. C. Sun, "Producing lignin-based polyols through microwave-assisted liquefaction for rigid polyurethane foam production," Maternité, vol. 8, no. 2, pp. 586-599, 2015.

[79] X. Huang, C. F. De Hoop, J. Xie, C.-Y. Hse, J. Qi, and T. Hu, "Characterization of biobased polyurethane foams employing lignin fractionated from microwave liquefied switchgrass," International Journal of Polymer Science, vol. 2017, Article ID 4207367, 8 pages, 2017.

[80] X. Huang, C. F. De Hoop, J. Xie, Q. Wu, D. Boldor, and J. Qi, "High bio-content polyurethane (PU) foam made from bio-polyol and cellulose nanocrystals (CNCs) via microwave liquefaction," Materials and Design, vol. 138, pp. 11-20, 2018.

[81] X. Y. Huang, F. Cornelis, X. P. Peng et al., “Thermal stability analysis of polyurethane foams made from microwave liquefaction bio-polyols with and without solid residue," BioResources, vol. 13, no. 2, pp. 3346-3361, 2018.

[82] S. Yang, D. B. Fan, and G. Y. Li, "Analysis of phenolic compounds obtained from bamboo microwave liquefaction for fast-curing phenol-formaldehyde resin preparation," Journal of Applied Polymer Science, vol. 136, no. 9, p. 46952, 2018.

[83] J. Feng, J. Jiang, C.-y. Hse et al., "Selective catalytic conversion of waste lignocellulosic biomass for renewable value-added chemicals via directional microwave-assisted liquefaction," Sustainable Energy \& Fuels, vol. 2, no. 5, pp. 1035-1047, 2018.

[84] J. Feng, C. Hse, Z. Yang, K. Wang, J. Jiang, and J. Xu, "Renewable platform chemicals from directional microwave-assisted 
liquefaction coupling stepwise extraction of waste biomass," Bioresource Technology, vol. 244, pp. 496-508, 2017.

[85] W. Xiao, A. Pang, X. Wang, J. Liu, and L. Han, "Separation and analysis of microwave-assisted liquefied products of corn stover," BioResources, vol. 9, no. 4, 2014.

[86] J. L. Xie, C. Y. Hse, T. F. Shupe, and T. X. Hu, "Physicochemical characterization of lignin recovered from microwaveassisted delignified lignocellulosic biomass for use in biobased materials," Journal of Applied Polymer Science, vol. 132, no. 40, p. 42635, 2015.

[87] H. Shao, J. Xie, C. F. De Hoop, J. Qi, H. Xiao, and Y. Chen, "Fractionation and Potential Applications of Components from Microwave Liquefaction of Chromate Copper Arsenate-Treated Wood," BioResources, vol. 13, no. 4, 2018.

[88] X. Y. Huang, F. Cornelis, J. L. Xie et al., "Thermal decomposition characteristics of microwave liquefied rape straw residues using thermogravimetric analysis," Journal of Thermal Analysis and Calorimetry, vol. 131, no. 2, pp. 1911-1918, 2018.

[89] J. Xie, C.-Y. Hse, C. F. De Hoop, T. Hu, J. Qi, and T. F. Shupe, "Isolation and characterization of cellulose nanofibers from bamboo using microwave liquefaction combined with chemical treatment and ultrasonication," Carbohydrate Polymers, vol. 151, pp. 725-734, 2016.

[90] X. Huang, C. F. De Hoop, F. Li et al., "Dilute alkali and hydrogen peroxide treatment of microwave liquefied rape straw residue for the extraction of cellulose nanocrystals," Journal of Nanomaterials, vol. 2017, Article ID 4049061, 9 pages, 2017.

[91] J. Xie, C.-Y. Hse, T. F. Shupe, H. Pan, and T. Hu, "Extraction and characterization of holocellulose fibers by microwaveassisted selective liquefaction of bamboo," Journal of Applied Polymer Science, vol. 133, no. 18, 2016.

[92] X. Y. Li, X. Q. Li, W. B. Li et al., "Determination of phenols in biomass corn straw liquefaction products," Journal of Beihua University (Natural Science), vol. 1, pp. 108-113, 2018.

[93] J. Cheng, R. Huang, T. Yu, T. Li, J. Zhou, and K. Cen, "Biodiesel production from lipids in wet microalgae with microwave irradiation and bio-crude production from algal residue through hydrothermal liquefaction," Bioresource Technology, vol. 151, pp. 415-418, 2014. 


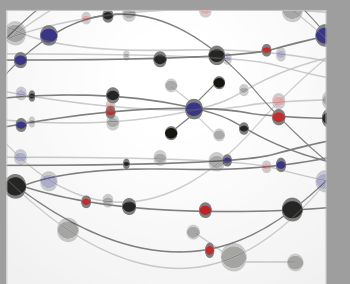

The Scientific World Journal
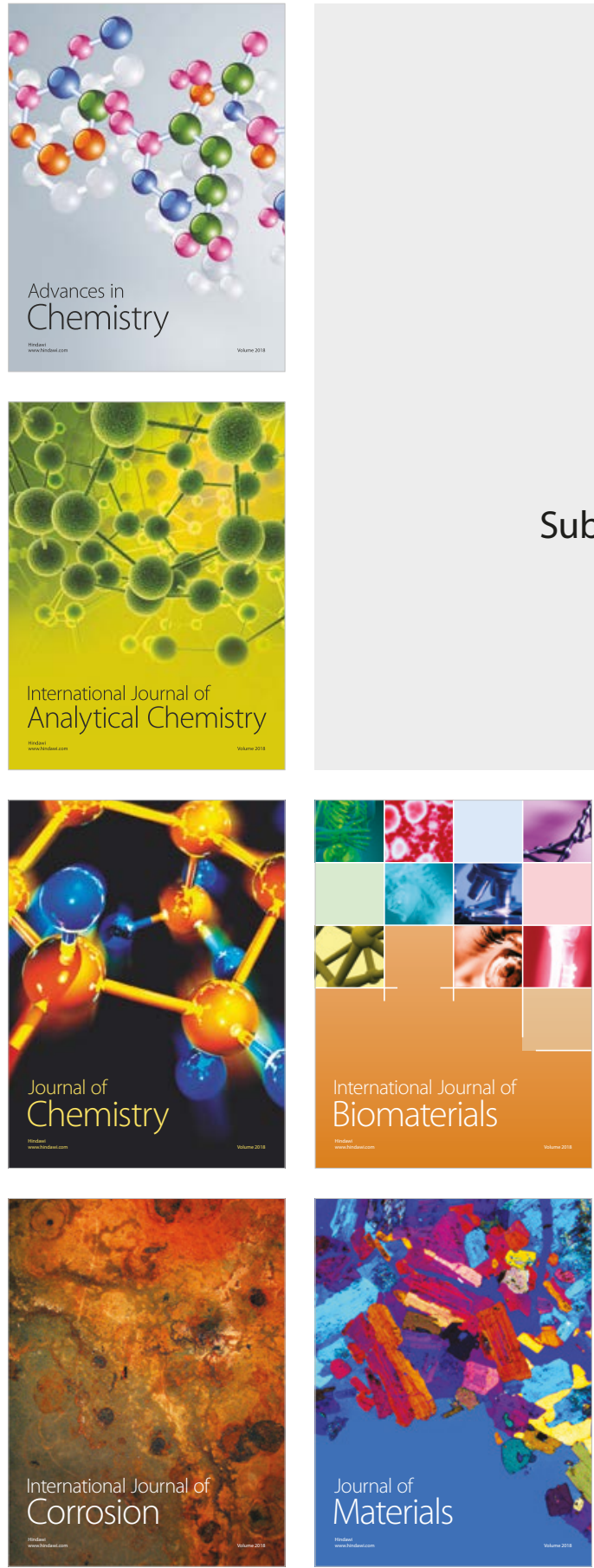

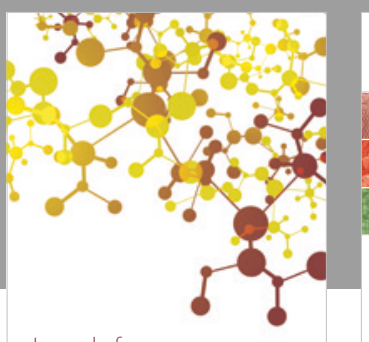

Journal of

Applied Chemistry
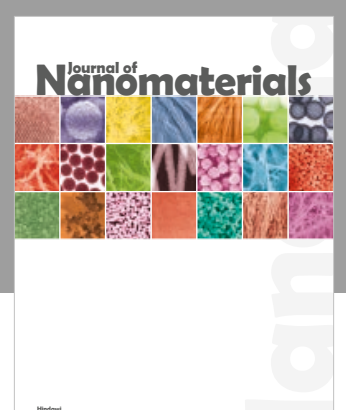

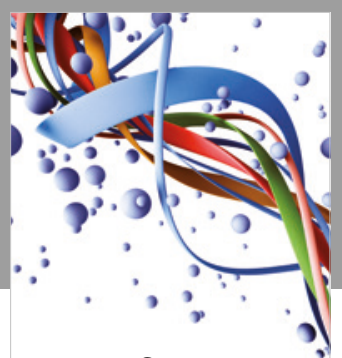

Scientifica

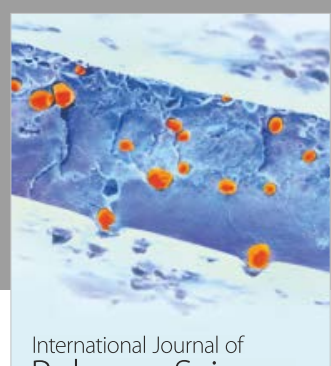

Polymer Science

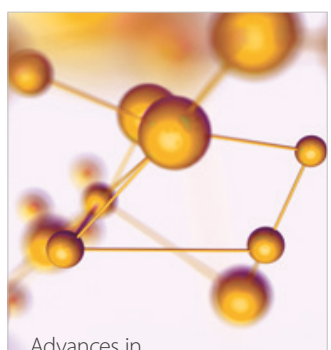

Physical Chemistry
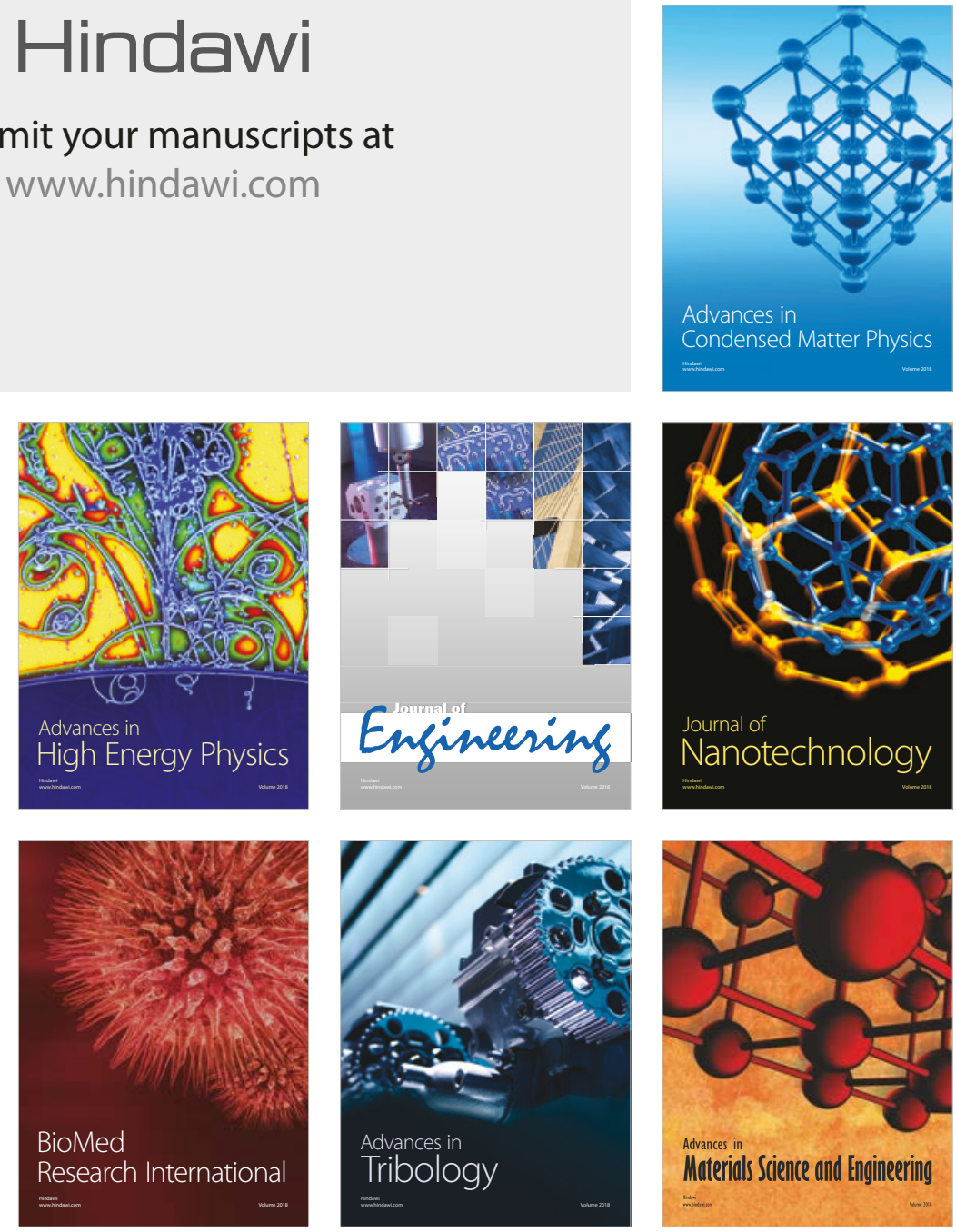